\title{
A Three Dimensional Symmetrical Fractal Tree Antenna Using Chemical Deposition Technique
}

\author{
S. Khobragade, S. Nalbalwar and A. Nandgaonkar \\ Dr. Babasaheb Ambedkar Technological University Lonere, Mangaon, Raigad, MH, India \\ \{svk2305@gmail.com,slnalbalwar@gmail.com, abnandgaonkar@yahoo.com\}
}

\begin{abstract}
A three dimensional symmetrical fractal tree antenna using chemical deposition technique is presented. The fractal antennas are used to enhance antenna properties due to their self - similarity behavior. The tree design Microstrip antenna provides miniaturization and multiband operation. The chemical deposition is one of the most interesting technique. Experimental result on the return loss over the band of 1 to $11 \mathrm{GHz}$ and radiation pattern were presented. Chemical deposition technique clearly indicate the shifting of all frequency bands from high frequencies to low frequencies. For all the resonant frequencies VSWR is less than two.
\end{abstract}

\section{Keywords: Fractal tree antenna, symmetrical antenna, chemical deposition, multiband antenna}

\section{Introduction}

Now a days, the Microstrip patch antenna due to their advantages like light weight, easy to fabricate, small size and low cost are widely used for satellite and wireless communication. The microstrip patch antenna (MSPA) has several applications such as global positioning system (GPS), bluetooth, WLAN, GSM, radar, satellite communication etc. But Microstrip patch antenna (MSPA) has disadvantages like low gain and narrow bandwidth. Improvement of frequency bandwidth is possible by increasing height of substrate. But by increasing height of substrate, antenna becomes bulky [1]. Therefore to enhance the bandwidth, the slot antenna of microstrip line is fed by fork like tuning stub [2]. The gain of the antenna is $2 \mathrm{~dB}$ and bandwidth is around $500 \mathrm{MHz}$. Fork-like tuning stub is used to improve bandwidth but it is complicated structure for fabrication [3].

Today's, antenna with multiband application is most desirable. Different techniques have been used to achieve multiband characteristic of antenna [4]-[6]. Dual and triple band antennas are obtained in [4] using U slot patch. In [5], defected ground structure is used to obtain tripleband antenna. Use of fractal geometry for patch design is one of the simplest techniques to achieve multiband antenna.Multiband Sierpinski Gasket is reported in [6]. Effect of change in flare angle of Sierpinski Gasket geometry onperformance of antenna is given in [7]. Fractal gives log periodic behavior because it has self-similarity characteristic. Itis possible to achieve desired spacing between $\log$ periodicbands as given in [8].

The fractal antenna is a set of independent radiating dipoles which distributed in space [9]. This paper gives contribution about multiband antenna with increased size, low cost and omnidirectional radiation pattern with less side lobe level. Also comparison of the simple fractal tree antenna and same antenna with chemical deposition technique is explained. Experimental results on the return loss and VSWR over the complete band at all the resonating frequencies were presented. The multiband electromagnetic of an antenna was studied by C. Puente et al. It is observed that the complete multiband pattern for return loss and VSWR was shifted in chemical deposition technique.

B. Iyer, S. Nalbalwar and R. Pawade (Eds.) ICCASP/ICMMD-2016. Advances in Intelligent Systems Research.

Vol. 137, Pp. 450-456.

(C) 2017- The authors. Published by Atlantis Press

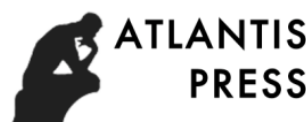

This is an open access article under the CC BY-NC license (http://creativecommons.org/licens)es/by-nc/4.) 


\section{$2 \quad$ Fractal Binary Tree}

Fractal Tree Microstrip Antenna is one which start with a stem and allows one of its end to branch off in two direction with specified angle. Next stage of the current iteration, each of these branches is allowed to branch out again, and this process can be continued infinitely as shown in figure 1. The primary objective of studying this geometry procedure is to verify the hypothesis developed for the relation between antenna resonance characteristics and the fractal dimension of the geometry. The angular splitting can vary the separation between the branches at each iteration. The relative length of each branch can vary in one stage in relation to the next. Fractal can be implemented as a function of geometrical design parameters such as the angle or the number of iteration. In this study, our fractal design on Microstrip Antenna is simulated with HFSS [11]. Iterated system Function (ISF) represent an extremely versatile method for conveniently generating a wide variety of useful fractal structures. These iterated function system are based on the application of series of affine transformation $\mathrm{W}_{\mathrm{s}}$ defined by

$$
W\left(\begin{array}{l}
x \\
y
\end{array}\right)=\left(\begin{array}{ll}
a & b \\
c & d
\end{array}\right)\left(\begin{array}{l}
x \\
y
\end{array}\right)+\left(\begin{array}{l}
e \\
f
\end{array}\right)
$$

Or equivalently,

$$
W(x, y)=(a x+b y+e, c x+d y+f)
$$

Where $\mathrm{a}, \mathrm{b}, \mathrm{c}, \mathrm{d}$, e and $\mathrm{f}$ are real numbers. Hence the affine transformation $\mathrm{w}$, is represented by six parameters.

$$
\left(\begin{array}{lll}
a & b & \vdots \\
c & d & f
\end{array}\right)
$$

Such that $\mathrm{a}, \mathrm{b}, \mathrm{c}$ and $\mathrm{d}$ control rotation and scaling. While e and $\mathrm{f}$ control linear translation. Now we can consider $\mathrm{W}_{1}$, $\mathrm{W}_{2}, \ldots \ldots ., \mathrm{W}_{\mathrm{N}}$ as a set of affine linear transformation, and let $\mathrm{A}$ be the initial geometry. Then a new geometry, produced by applying the set of transformation to the original geometry, A, and collecting the results from $\mathrm{W}_{1}(\mathrm{~A})$, $\mathrm{W}_{2}(\mathrm{~A}), \ldots \ldots, \mathrm{W}_{\mathrm{N}}(\mathrm{A})$ can be represented by

$$
W(A)=\bigsqcup_{n=1}^{N} W_{n}(A)
$$

Where $\mathrm{W}$ is known as the Hutchinson operator. A fractal geometry can be obtain by repeatedly applying $\mathrm{W}$ to the previous geometry. For example, if the set A0 represents the initial geometry, then we will have

$$
A_{1}=W\left(A_{0}\right), A_{2}=W\left(A_{1}\right), \ldots \ldots . . A_{k+1}=W\left(A_{k}\right)
$$

An integrated function system generates a sequence that converges to the final image which is nothing but the fractal design [12].

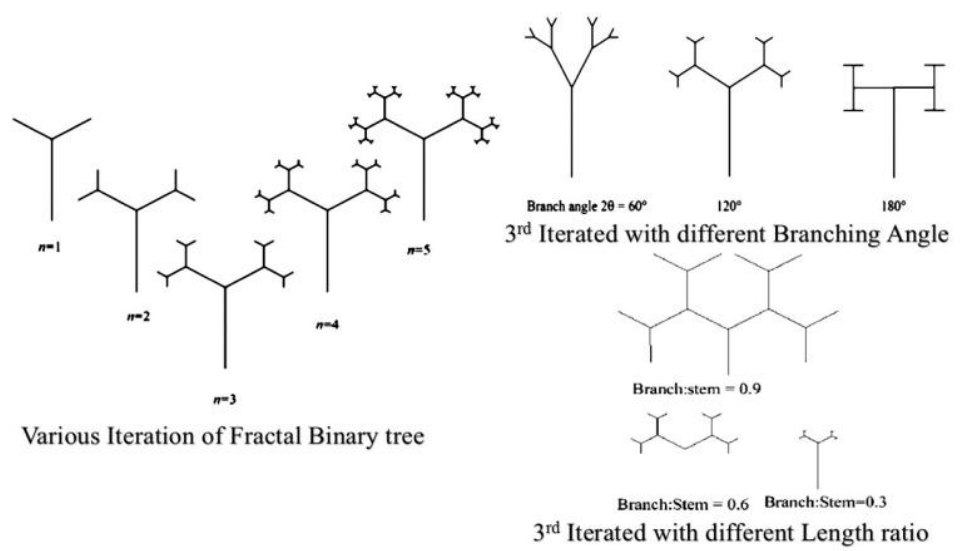

Fig.1. Proposed Fractal Binary Tree Antenna 


\section{Antenna design}

The proposed antenna design is simulated designed using HFSS. The antenna is constructed using FR-4 (lossy) substrate which is low cost dielectric substrate material with $1.6 \mathrm{~mm}$ height and relative permittivity is $\varepsilon_{r}=4.4$ with loss tangent $(\tan \delta) 0.02$. The strip-line feeding is used because we can easily match the input impedance and can be easily fabricated [10]. The proposed patch antenna has dimensions of $\mathrm{L} \times W$ is obtained to resonate the antenna at multiple frequencies as shown in figure 2 which is printed on the substrate of dimensions $80 \mathrm{~L} \times 100 \mathrm{~W} \times 1.6 \mathrm{~h} \mathrm{mm^{3 }}$.
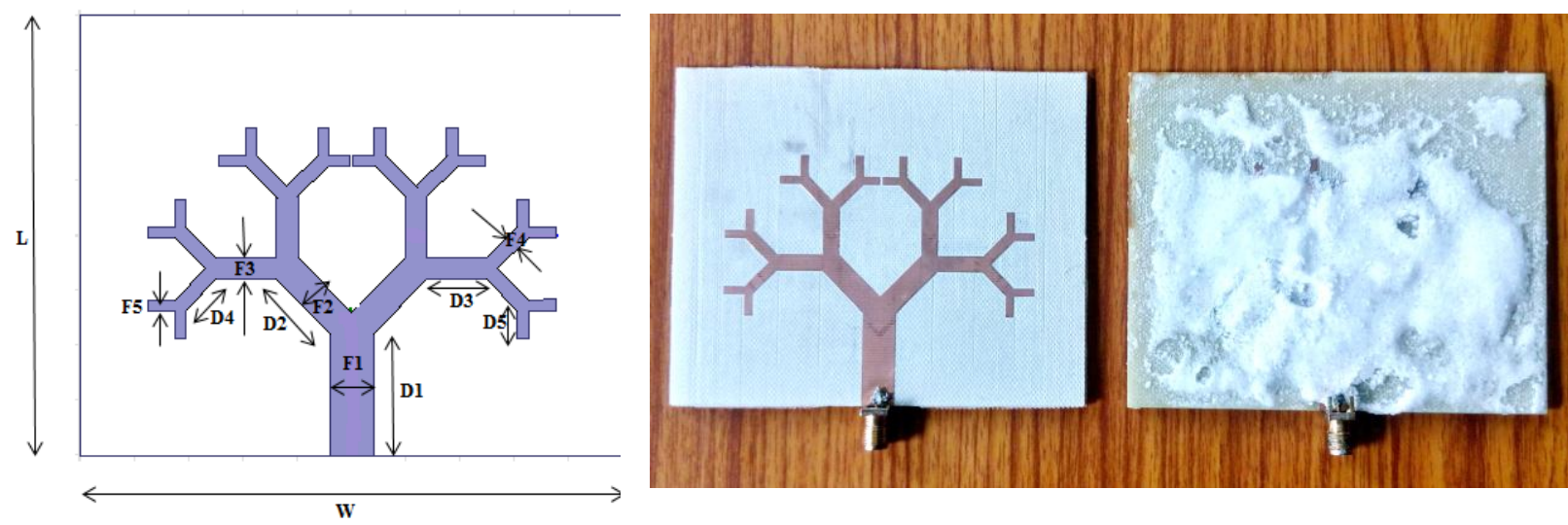

Fig.2. Proposed Antenna Design and Photos of Fabricated Antenna without and with Chemical Deposition

Fig.1 also shows the fractal tree antenna with the given specification. One antenna without and second antenna with the random chemical deposition of $\mathrm{NaCl}$ over same antenna. Table I. gives the specifications of the antenna parameters of the proposed antenna.

Table I. Antenna Dimensions Shown In Fig.1

\begin{tabular}{|l|l|l|l|}
\hline Parameters & Size (mm) & Parameters & Size (mm) \\
\hline W & 100 & D5 & 5 \\
\hline L & 80 & F1 & 8 \\
\hline D1 & 22 & F2 & 6 \\
\hline D2 & 14 & F3 & 4 \\
\hline D3 & 11 & F4 & 3 \\
\hline D4 & 8 & F5 & 2 \\
\hline
\end{tabular}

\section{Results}

\subsection{Simulated Results of Antenna}

The simulation results of proposed antenna is obtained using HFSS software.

Return Loss. Fig. 3 shows the return loss versus frequency plot of design antenna. In simulation result, proposed antenna gives good impedance matching at resonant frequency $5.8 \mathrm{GHz}, 7.1 \mathrm{GHz}, 8.2 \mathrm{GHz}, 9.5 \mathrm{GHz}, 10.3 \mathrm{GHz}$ and $10.8 \mathrm{GHz}$ with maximum value of $-18.579 \mathrm{~dB}$ 
VSWR Plot. Fig. 4 shows the voltage standing wave ratio versus frequency plot in GHz of proposed antenna. The ideal value of VSWR is 1 . The antenna shows the good impedance matching.

Gain of The Proposed Antenna. Fig.5 shows the gain $(\mathrm{dB})$ versus frequency $(\mathrm{GHz})$ plot. The gain of proposed antenna at different resonant frequency $5.8 \mathrm{GHz}, 7.1 \mathrm{GHz}, 8.2 \mathrm{GHz}, 9.5 \mathrm{GHz}, 10.3 \mathrm{GHz}$ and $10.8 \mathrm{GHz}$

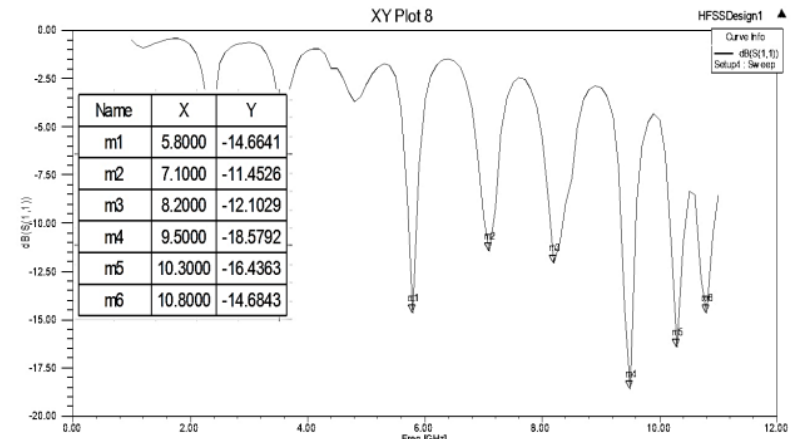

Fig.3. Return Loss Plot for Design Antenna

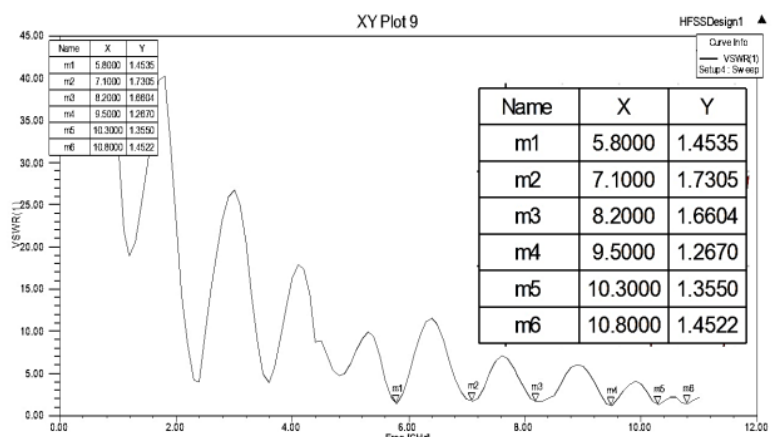

Fig.4. VSWR versus Frequency Plot $(\mathrm{GHz})$

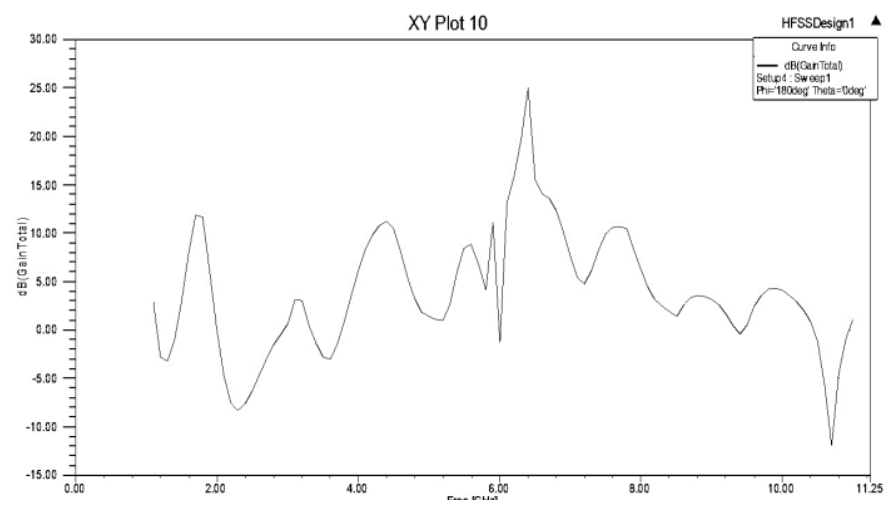

Fig.5. Gain (dB) versus Frequency $(\mathrm{GHz})$ Plot

Radiation Pattern Of Antenna. Fig.6(a) shows the radiation pattern of design antenna for frequency $5.8 \mathrm{GHz}$ at phi=0 degree and phi=90 degree. Similarly figure $6(\mathrm{~b})$ to $6(\mathrm{f})$ shows the radiation pattern from the resonant frequency range from $7.1 \mathrm{GHz}, 8.2$ $\mathrm{GHz}, 9.5 \mathrm{GHz}, 10.3 \mathrm{GHz}$ and $10.8 \mathrm{GHz}$. The radiation pattern of proposed antenna shows the omnidirectional behavior. The radiation patternhave low side lobe level.

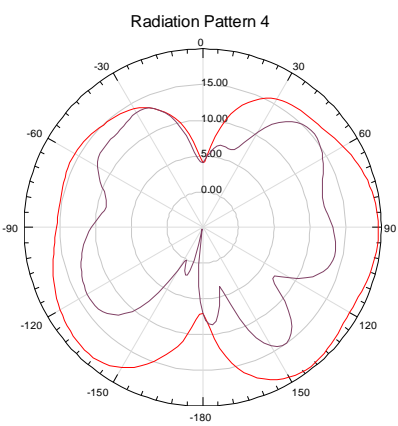

(a)

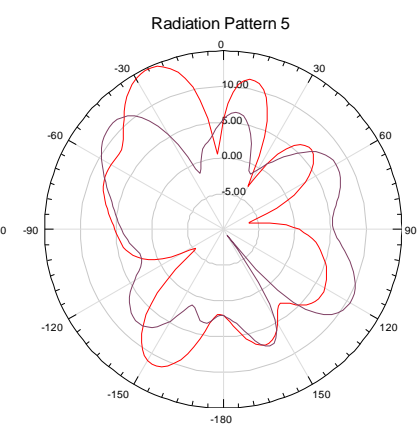

(b)

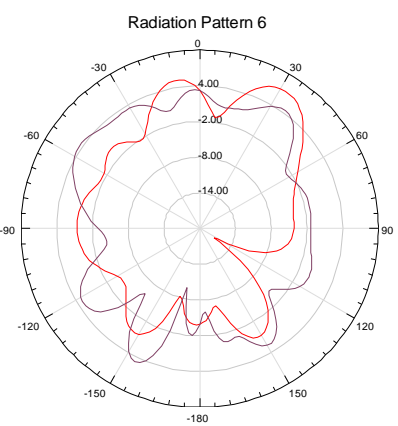

(C) 


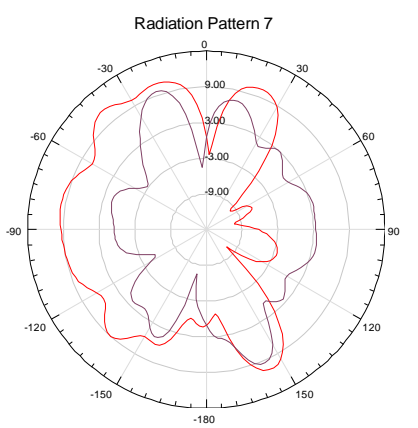

(d)

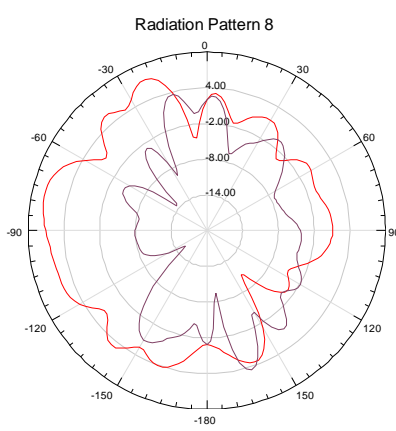

(e)

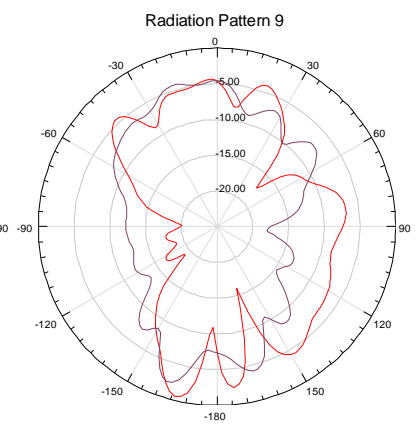

(f)

Fig.6. Radiation pattern of antenna at phi $=0$ degree and phi $=90$ degree at (a) $5.8 \mathrm{GHz}$ (b) $7.1 \mathrm{GHz}$ (c) $8.2 \mathrm{GHz}$ (d) $9.5 \mathrm{GHz}$, (e) $10.3 \mathrm{GHz}$ and (f) $10.8 \mathrm{GHz}$

Table II summarizes the simulation result in terms of resonant frequency, return loss bandwidth and VSWR bandwidth. Measured result shown in the next section perfectly matches with the simulation results. Simulation result and measured results provides 6 frequency bands shown in table.

Table II. Resonant frequency, Impedance Bandwidth, and VSWR

\begin{tabular}{|l|l|l|l|l|l|l|}
\hline SN & 1 & 2 & 3 & 4 & 5 & 6 \\
\hline Res. & 5.8 & 7.1 & 8.2 & 9.5 & 10.3 & 10.8 \\
Freq. & $\mathrm{GHz}$ & $\mathrm{GHz}$ & $\mathrm{GHz}$ & $\mathrm{GHz}$ & $\mathrm{GHz}$ & $\mathrm{GHz}$ \\
\hline & 5.7 & 7.02 & 8.14 & 9.34 & 10.17 & 10.63 \\
Imp. & - & - & - & - & - & - \\
B/W & 5.86 & 7.17 & 8.35 & 9.59 & 10.44 & 10.93 \\
& $\mathrm{GHz}$ & $\mathrm{GHz}$ & $\mathrm{GHz}$ & $\mathrm{GHz}$ & $\mathrm{GHz}$ & $\mathrm{GHz}$ \\
\hline VSWR & 1.45 & 1.73 & 1.66 & 1.26 & 1.35 & 1.45 \\
\hline
\end{tabular}

\subsection{Measured Result of an Antenna}

Antenna is tested in Terna Engineering College New Mumbai with Agilent Vector Network Analyzer. Measured result shown here for the comparison. Two antennas are tested one without deposition and other with $\mathrm{NaCl}$ deposition.

Measured result for the return loss of the antenna is perfectly matched with the simulated return loss result shown in Fig.7. Range of the resonant frequencies varies from $5.8 \mathrm{GHz}$ to $10.8 \mathrm{GHz}$ for both the results.

Fractal tree Microstrip antenna is coated with the $\mathrm{NaCl}$. NaCl has the property that the attraction between the $\mathrm{Na}^{+}$ and $\mathrm{Cl}^{-}$ions in the solid is so strong that only highly polar solvents like water dissolve $\mathrm{NaCl}$ well. When dissolved in water, the sodium chloride framework disintegrates as the $\mathrm{Na}^{+}$and $\mathrm{Cl}^{-}$ions become surrounded by the polar water molecules. These solutions consist of metal aqua complex with the formula $\left[\mathrm{Na}\left(\mathrm{H}_{2} \mathrm{O}\right)_{8}\right]^{+}$, with the $\mathrm{Na}-\mathrm{O}$ distance of $250 \mathrm{pm}$. The chloride ions are also strongly solvated, each being surrounded by an average of 6 molecules of water. Solutions of sodium chloride have very different properties from pure water. The freezing point is $-21.12{ }^{\circ} \mathrm{C}$ $\left(-6.02{ }^{\circ} \mathrm{F}\right)$ for $23.31 \%$ of salt, and the boiling point of saturated salt solution is near $108.7^{\circ} \mathrm{C}\left(227.7^{\circ} \mathrm{F}\right)$. From cold solutions, salt crystallizes as the dehydrate $\mathrm{NaCl} \cdot 2 \mathrm{H}_{2} \mathrm{O}$.

We dissolve $\mathrm{NaCl}$ in boiling water and the deposit the water over the Microstrip Antenna and keep the Antenna to cool such that $\mathrm{NaCl}$ layer is deposited over it. This is random deposition. Normal antenna and antenna with $\mathrm{NaCl}$ deposition is shown in figure 8 . 


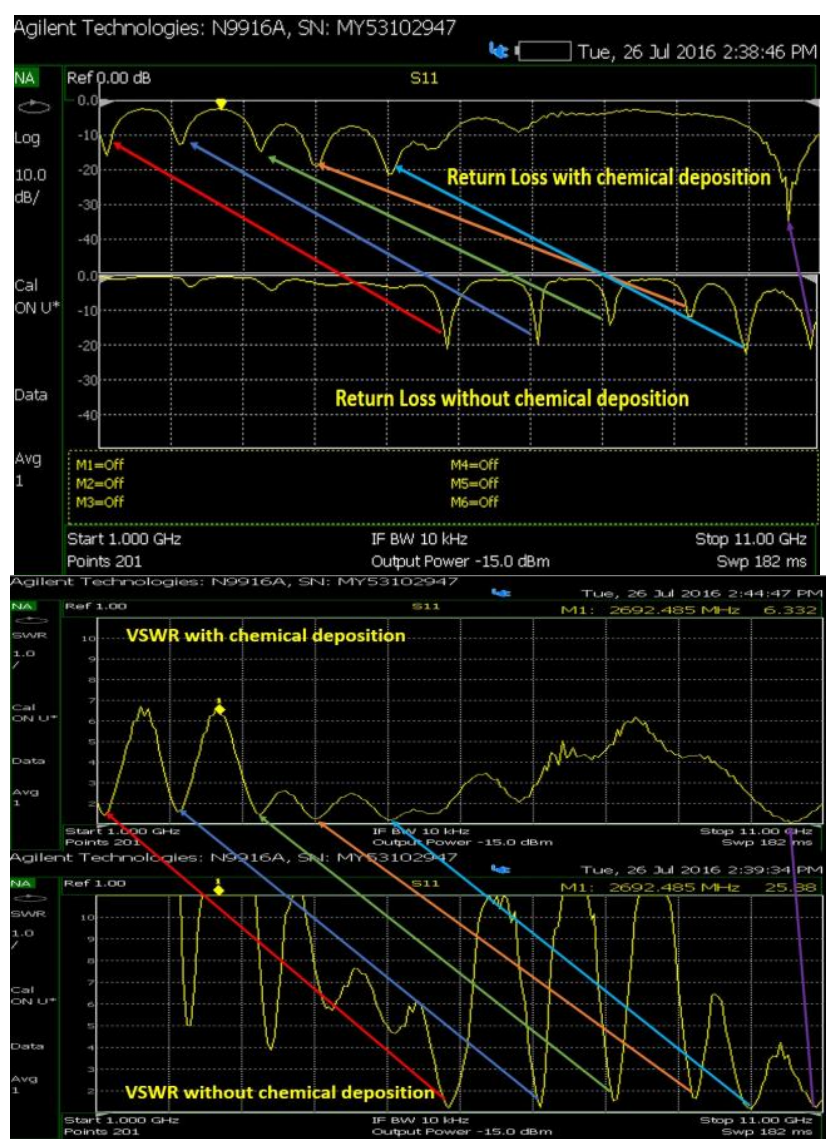

Fig.7.Return Loss and VSWR Comparison

\section{Conclusion}

In this paper, a fractal antenna realized by using chemical deposition technique. Antenna is simulated and tested in the frequency range $1-11 \mathrm{GHz}$, on the return loss, VSWR and radiation patterns show a multiband electromagnetic behaviour.

The main novel property of this structure is the shift in the resonant frequency for the antenna with chemical deposition techniques from high frequency range to low frequency range. The resonant frequencies of the structure are related to the length distribution over the fractal shape. The self-similarity behaviour can be explained by assuming that the structure is composed with independent radiating dipoles randomly distributed in space, and each branch of the tree antenna resonated at a wavelength four times its length. Finally, fractal-tree structure with multiband behaviour, good gain and radiation characteristics, compact size and natural shape, represents a new engineering solution.

\section{References}

[1] Balanis C A: Antenna theory Analysis and design, Second ed., John Wiley and Sons Inc., 1997.

[2] Jia-Yi Sze, Kin-Lu Wong: Bandwidth enhancement of a Microstrip line fed printed wide slot antenna, Antennas and Propagation, IEEE transaction on, vol-49, no. 7, Pp. 1020, 1024, (July 2001).

[3] Lui W J, Cheng C H, Cheng Y, and Zhu H: Frequency notched ultra wide band Microstrip slot antenna with fractal tuning stub, Electronics Letters, Volume 41, no. 6, Pp. 294-296, (March 2005). 
[4] Lee K.F, Shing Yang, Kishk A A: Dual and multiband U-slot patch antennas, Antennas and wireless propagation letters, IEEE, volume 7, Pp.645-647, (2008)

[5] Wen-Chung Liu, Chao Ming Wu, Yang Dai: Design of triple frequency Microstrip fed monopole antenna using defected ground structure, Antenna and propagation, IEEE transaction on, volume 59, no7, Pp 24572463, (July 2011)

[6] Puente Baliarda C., Romeu J., Pous R., Cardama A: On the behavior of the Sierpinski multiband fractal antenna, Antennas and propagation, IEEE transaction, vol-46, no-4, Pp 517-524, (April 1998)

[7] Baliard C P, Borau C B, Rodero M N, Robert J R: An iterative model for fractal antennas: application to Sierpinski gasket antenna, Antenna and propagation, IEEE transaction, vol-48. Pp 713-719, (May 2000)

[8] Puente C, Romeu J, Bartoleme R, Pous R, Perturbation of the Sierpinski antenna to allocate operating bands, Electronics Letters, vol. 32, pp. 2186-2188, (November 1996)

[9] Hatem Rmili, Otman El Mrabet, Jean-Marie Floc'h, and Jean-Louis Miane: Study of an ElectrochemicallyDeposited 3-D Random Fractal Tree-Monopole Antenna, IEEE Transactions on Antennas and Propagation, Vol. 55, No. 4, Pp. 1045-1050, (April 2007)

[10] Ahmed H Reja: Study of Microstrip feed line patch antenna, Antennas and Propagation International Symposium, vol-27, Pp 340-342, (December 2009)

[11] Naghshvarian Jharomi, Falahati A, Edwards R M: Application of Fractal Binary tree slot to design and construct a dual band notch CPW - Ground - fed ultra wide band Antenna, Published in IET Microwave, Antenna \& Propagation, ISSN 1751-8725 (May 2011)

[12]Douglas H Werner and Suman Ganguly: An Overview of Fractal Antenna Engineering Research 